\title{
O HISTORIADOR COMO INQUISIDOR OU COMO ANTROPÓLOGO? Um Questionamento para os "Historiadores Orais"
}

\author{
Dante Marcello Claramonte Gallian*
}

\begin{abstract}
RESUMO: Chamar atençáo dos historiadores que trabalham com documentos de estrutura diaIógica, principalmente os oriundos da técnica de História Oral, para os problemas epistemológicos e metodológicos da Nova Antropologia, é o principal objetivo deste artigo.

Partindo da analogia que o historiador Carlo Ginzburg propóe entre o antropólogo e o inquisidor, pretencle-se recolocar a problemática da relação entre o pesquisador e o narrador no processo de criação e interpretaçĩo das fontes orais.
\end{abstract}

PALAVRAS-CHAVE: História Oral, Antropologia, Relação entrevistaclor-entrevistado, documentos dialógicos, Fontes Orais.

A história cultural, dentro da sua trajetória, contou com inúmeras contribuiçôes e influências, entretanto, pode-se dizer que a antropologia teve e continua tendo um papel central na sua evolução.

A influência da antropologia sobre a história pode ser identificada não apenas no aparecimento de novos temas históricos, mas, principalmente, nas redefinições teóricas e metodológicas dos trabalhos mais recentes. Hoje, para o historiador que busca estudar as dimensões culturais de uma sociedade, torna-se imperioso a familiarização com os problemas conceituais, metodológicos e mesmo epistemológicos levantados pela antropologia, pois só assim ele estará mais apto a enlrentar os desafios que as novas perspectivas e documentos the apresentam.

Neste sentido, o texto de Carlo Ginzburg' sobre a analogia entre o inquisidor e o antropólogo se apresenta como muito elucidativo.

- Mestre em História Social pela USP.

1 GINZBURG, Carlo, "O Inquisidor como Antropólogo" in América, Américas, Revista Brasileira de História, São Paulo. ANPUH/Marco Zero, n. 21 - setembro 90/ fevereiro 91, pp. 9-20. 
GALLIAN, Dante Marcello Claramonte. O historiaclor como inquisidor ou como antropólogo?

Um questionamento para os "historiadores orais".

Apesar de centrar-se em um tipo específico de documento, os inquéritos inquisitoriais da Baixa Idade Média e princípios da Idade Moderna, a problemática que Ginzburg levanta a respeito da estrutura dialógica dos testemunhos históricos e o método para decifrá-los, deveria ser considerada por todo e qualquer historiador que se utiliza de fontes análogas; isto é: documentos que possuem uma estrutura dialógica explícita - "como nas séries de questões e respostas que pontuam tanto um processo inquisitorial quanto uma transcrição de conversas entre um antropólogo e seu informante" - ou mesmo implícita - "como em anotações de pesquisa etnográfica de campo descrevendo um ritual, um mito, um instrumento." 2

Neste sentido, a analogia entre o inquisidor e o antropólogo revela elementos importantes ao historiador e pode lhe inspirar novas analogias a partir de personagens que the sejam mais próximos e adequados, de acordo com o tipo de documentação e de metodologia de que se utiliza.

De minha parte, confesso que, ao ler o texto de Ginzburg, não pude deixar de tentar reinventar seu experimento comparativo a partir das categorias documentais e metodológicas que me são mais familiares: as da História Oral. E, neste sentido, inspirado na analogia de Ginzburg, gostaria de propor uma discussão sobre a História Oral partindo das posturas que assume o "historiador oral" em sua tarefa de produzir documentos: agirá ele como o antropólogo ou como o inquisidor?

Creio que tal discussão possa ser muito útil já que a História Oral vem ganhando uma grande importância na historiografia atual ${ }^{3}$, no sentido em que o documento oral vem se tornando fundamental e, em certos casos, imprescindível para certos temas da história cultural.

Comentando o debate iniciado por Keith Thomas e Hildred Geertz no Journal of Interdisciplinary History, Ginzburg coloca que o diálogo entre historiadores e antropólogos é difícil. Segundo ele, "A obtenção da informação parece crucial neste contexto. Os historiadores das sociedades do passa-

$2 \quad$ Ibid., p.14.

3 No caso do Brasil a História Oral tem sido utilizada por muitos historiadores e de maneira cach vez mais acentuada. Diante disto ten se visto uma grande mobilização em torno a questōes temáticas, teóricas, metodológicas e técnicas através da realizaçāo de encontros e seminários, como o realizado pelo MIS de Sâo Paulo em novembro de 1991. Tudo isto vem culminando na organização de uma Assucinçẫo Brasileira de História Oral, cujas sementes foram lançadas em agosto deste ano (1992) na Universichude de São Paulo durante o Congresso América 92, aproveitando a presença de estudiosos e especialistas de todo o país. 
do não podem produzir as suas fontes como fazem os antropólogos. Fichas de arquivo, vistas deste ângulo, Não podem substituir os gravadores." ${ }^{4}$

Ora, tal diferença na forma de obtenção de informação, deixa de existir quando o historiador trabalha com a História Oral, pois ele, assim como o antropólogo, produz suas próprias fontes, utilizando-se fundamentalmente do gravador. Neste caso, fica evidente que o diálogo entre os dois torna-se não apenas mais procedente mas, principalmente, mais necessário.

O que se percebe, entretanto, quando analísamos certas obras consideradas fundamentais para o trabalho com História Oral, é que esse diálogo com a antropologia - e aqui me refiro essencialmente à Nova Antropologia norteamericana, com destaque para a obra de Clifford Geertz $z^{5}$ - simplesmente nấo existe.

Para autores consagrados como Paul Thompson, David Henige, Trevor Lummis e Ronald Fraser , a grande vantagem da Historia Oral, alem da sua dimensão ideologicamente democratizante, no sentido em que delega a voz aos silenciados pela história oficial, está exatamente na possibilidade do historiador produzir suas fontes, intervindo diretamente na obtenção de informaçőes. Citando a Lummis:

"The great advantage of retrospective interview is that is enables historians to intervene directly in the generation of historical evidence relating to the recent past, and it become possible for the historian to colect the type of evidence wich customary documentary and material sources have not suplied." 7

Ao contrário dos historiadores que trabalham com a documentação "tradicional", ou seja, indireta, cuja produção não esteve determinada por uma intencionalidade científica, o "historiador oral" estaria obtendo a informação de forma direta, "limpa", "descontaminada" dos preconceitos e interpretações inoportunas que dificultam a "reconstituição" histórica de culturas e mentalidades do passado recente. Segundo Thompson, a História Oral,

4 GINZBURG, Op.Cit., p.12.

5 GEERTZ, Cliford, El Antropologo como Autor, Barcelona, Paidos Studio, 198:

6 THOMPSON, Paul, The Voice of Past: Oral History. Oxford, Oxford Press, 1978; LUMMIS, Trevor, Listening to History, New Jersey, Barnes \& Nobel Books, 1987; HENIGE, David P., Oral Historiography. London/New York, Longman, 1982; FRASBR, Ronald, Blood of Spain; an Oral History of Spanish Civil War. New York, Pantheon books, 1979.

LUMMIS, T., Op.Cit., p.7. 
GALLIAN, Dante Marcello Claramonte. O historiador como inquisidor ou como antropólogo? Um questionamento para os "historiadores orais".

através da técnica de entrevista retrospectiva possibilita "a more realistic reconstruction of the past." 8

Isto porque o historiador é o mais capacitado entrevistador quando o objetivo da entrevista é obter informações sobre o passado. Ele deverá perguntar, intervir a partir de preocupações e intenções propriamente históricas, dentro do tema específico da pesquisa, ao contrário de qualquer outro entrevistador, cuja as intenções não sejam estas. Um "historiador oral" realizará uma entrevista táo completa e consistente quanto maior for seu conhecimento sobre o tema que se está pesquisando, porque ele intervirá de maneira objetiva, sabendo identificar o fato histórico, separando-o da interpretação ou das impressōes subjetivas do informante. Também poderá identificar o grau de fidedignidade de cada depoimento colhido, percebendo se o informante mente ou diz a verdade. Enfim, ele agirá como um veradeiro inquisidor da história; aquele que busca a verdade sobre o passado através daqueles que são suas "testemunhas vivas".

Ora, o que se pode concluir disto tudo é que as posturas destes autores, apesar da modernidade de suas intenções políticas e ideológicas e de suas perspectivas temáticas, continuam um tanto arcaicas dos pontos de vista conceitual, metodológico e, principalmente, epistemológico. Percebe-se, sem muita dificuldade, um posicionamento ingênuo e positivista diante daquilo que chamam de informação e de documentação e uma disposição muito mais inquisitorial do que antropológica naquilo que chamam de "entrevista retrospectiva". Fica óbvio o desconhecimento, por parte destes autores, do problema da "neutralidade da memória" e da "neutralidade do texto", tal como ele é analisado por Ginzburg e, antes dele, por Clifford Geertz.

Com relação ao problema da "neutralidade da memória" não gostaria de me demorar, mesmo porque este mereceria um texto a parte, já que aqui a preocupação central está em discutir as contribuições da antropologia, cujo objeto fundamental é a recriação cultural no presente e não no passado. De qualquer forma, caberia apenas dizer que a memória individual não pode ser entendida como uma espécie de simples depósito acumulador de experiências que ficam ali guardadas até que sejam resgatadas ou "lembradas", com maior ou menor clareza, mas sempre objetivamente, através do esforço da consciência que "rememora".

Tal perspectiva estática e positivista da memória não leva em consideração a sua estrutura ao mesmo tempo dinâmica e dialógica. Sim, porque 
enquanto dialógica a memória é dinâmica e vice-versa. A memória é, pois, um processo; um processo de diálogo entre o presente e o passado do indivíduo, envolvendo os seus mais diversos níveis: o consciente, $o$ inconsciente, o supra-consciente. A memória pressupöe a alteridade e a dinâmica do próprio indivíduo: não só o presente é experimentado subjetivamente, mas também o passado é experimentado subjetivamente no presente.

Ora, se a memória, que aparece como fonte de informação sobre o passado, não pode ser considerada neutra, tampouco e muito menos ainda será neutro o texto resultante de uma "entrevista retrospectiva". Aqui, somada à própria alteridade subjetiva soma-se outra, muito explorada pela antropologia: a alteridade inter-subjetiva. Porém, mesmo neste ponto, os autores consagrados da História Oral parecem não concordar com os antropólogos.

Apesar de frisarem o papel do historiador na obtenção de informações e reconhecerem os problemas existentes na relaçăo entre entrevistador e entrevistado, estes autores não consideram a intervenção daquele como algo que interfira na qualidade da informação. Esta, quando muito, poderá vir "contaminada" ou "interpretada" pelas impressões e idéias do informante, mas nunca pelas do historiador, pois afinal seu papel é o de apenas perguntar, nunca o de responder.

O que se deixa de perceber aqui é a questăo do poder que encerra a relação entre indivíduos. Talvez nos textos inquisitoriais da Baixa Idade Média e princípios da Idade Moderna a desigualdade em termos de poder (tanto real quanto simbólica) apareça de forma mais explícita no texto, porém esta desigualdade (agora bem mais simbólica do que real) não deixa de existir nos textos produzidos pela História Oral no século XX. Ainda hoje, como na época da inquisiçáo - guardadas as devidas proporções - grande parte dos trabalhos de História Oral continuam se baseando no velho esquema "monológico", no sentido em que as respostas do informante não passam, muitas vezes, de um simples eco das perguntas do entrevistador.

Neste caso o historiador está, contrariamente ao que ele pensa, definindo aquilo que será considerado realidade ou fato histórico, utilizando-se do informante como forma de confirmar ou, o que é mais comum, simplesmente ampliar o fato já definido, descobrindo novos detalhes e preenchendo lacunas da realidade histórica?.

9 Sobre a questăo das estratégias da memória histórica como instauradora e reiteradora do fato histórico ver o trabalho de VESENTINI, Carlos Alberto, A Teia do Fato; uma propasta de estudo sobre memória histórica. Tese de doutoramento, mimeo., São Paulo, FFLCH - USP, 1982. 
GALLIAN, Dante Marcello Claramonte. O historiador como inquisidor on como antropólogo?

Um questionamento para os "historiadores orais".

A superação do mito da "neutralidade do texto" deve muito à "consciência textual", que, nos últimos anos, como coloca Ginzburg, "veio para a linha. de frente entre os antropólogos, sendo mais ou menos diretamente inspirada pela obra de Clifford Geertz."10

Para Geertz, o texto deve ser visto como resultado de uma inter-relaçăo onde se mesclam as subjetividades. Neste sentido, a consciência e a explicitação do papel do antropólogo ou do etnógrafo como autor torna-se fundamental. "'O que faz o etnógrafo? - ele escreve', responde ironicamente Clifford Geertz"11. Geertz ressalta o papel literário que desempenha o antropólogo; para este, o valor do texto não está em convencer o leitor da "verdade", mas sim em convencê-lo de que o autor "esteve lá"("being there"), no campo.

Isto náo significa, entretanto, que o texto antropológico tenha apenas valor literário. Como coloca Ginzburg, "o ceticismo refinado que tem inspirado a rejeição da assim chamada 'falácia referência' parece uma perigosa armadilha" ${ }^{12}$. É certo que se deve dismitificar o conceito de neutralidade, porém não eliminar a dimensão da realidade e da objetividade. A interpretação das culturas é sempre uma tradução dos códigos do outro para o código cultural e pessoal daquele que escreve - e não pode ser de outra forma. Explicitar-se como autor é pois reconciliar-se com a dimensão da objetividade na antropologia.

Como coloca Clifford Geertz, em ensaio no qual compara criticamente a obra "científica" de Malinowski com seu diário íntimo,

"El problema, por plantearlo en términos tan prosaicos como sea posible, es el de cómo representar el proceso de investigación en el producto de la investigación; escribir etnografía de tal forma que resulte posible conducir la propia interpretación personal de determinada sociedad, cultura, modo de vida o lo que sea, a una relación inteligible. $O$, por decirlo rápidamente de otro modo, antes de que la psicología pueda colocarse de rondón, se trata de ver cómo introducir un autor yo-testifical en una historia dedicada a pintar a otros. Comprometerse con una concepción esencialmente biográfica del

\footnotetext{
10 GINZBURG, C., Op.Cit., p. 16.

11 Idem Ibidem.

12 Idem Ibidem.
} 


\begin{abstract}
'Estar All', antes que con una de tipo reflexivo, aventurero u obsevacional, es comprometerse con un enfoque confesional de la construcción textual. La persona real que Lévi-Strauss, Evans-Pritchard y Malinowski han intentado confinar en sus fabulaciones, memorias o ensofiaciones, ese yo creatural que ha llevado a cabo cosas extrañas y sufrido otras no menos raras, fluye ahora hacia el interior mismo de la obra.El más directo modo de llevar a efecto el trabajo de campo como un encuentro personal $y$, al mismo tiempo, la etnografia como relato fiable, es convertir la forma de diaro que Malinowski empleó para confinar sus pensamientos impuros (...), en un género ordenado y público, algo que todo el mundo pueda leer." 13
\end{abstract}

Ao mesmo tempo em que desmitificou a idéia de neutralidade, a "consciéncia textual", ao reconhecer a disposição "monológica" dos textos produzidos pela antropologia tradicional, acabou colocando em cheque a sua própria perspectiva metodológica. Percebeu-se que mais do que um simples eco das perguntas do entrevistador, a documentação deveria ser a textualização da inter-subjetividade, 0 que levou a se entender o trabalho de campo como uma "collaborative enterprise" ${ }^{14}$. Daí a revoluçăo nas técnicas de entrevista - que passam a ser nảo-diretivas -, a afirmação da pesquisa participante, a preocupação com as dimensões éticas da pesquisa.

Em outras palavras, a antropologia deixou de ver o outro como um simples "meio de informação" sobre a "realidade cultural" a ser "resgatada", passando a considerá-lo um sujeito, que através de sua narrativa, está "construindo e reconstruindo" 15 sua realidade social e individual; seu presente e seu passado. Ocorre, assim, em relação à postura tradicional, um deslocamento do "centro da objetividade", e a possibilidade de poder conhecer e interpretar a cultura do outro passa, necessariamente, pelo diálogo que se estabelece entre os sujeitos, no encontro dos seus discursos e no cruzamento de seus universos culturais.

\footnotetext{
13 GEERTZ, C., Op.Cit., p. 94.

14 Ver, neste sentido, BURNER, Edward M. and PLATTNER, Stuart, Text, Plays and Story: The Construction and Reconstruction of Self and Society. Washington, American Ethnological Society, 1984.

Idem Ibidem.
} 
GALLIAN, Dante Marcello Claramonte. O historiador como inquisidor ou como antrop6logo? Um questionamento para os "historiadores orais".

Toda esta nova dimensão da pesquisa antropológica tem tido ressonância em alguns autores que de uma forma ou de outra começam a desvencilhar a História Oral de seu sentido "inquisitorial" e de sua pretensão de "neutralidade científica".

A preocupação com a opinião e os sentimentos de um entrevistado que é transformado "à força" em informante frente às perguntas, o gravador e o "método científico" de um pesquisador aparece, por exemplo, como tema de um romance que se tornou imprescindível a todo aquele que queira se aventurar na História Oral. Trata-se da obra do mexicano José Woldenberg, Las Ausencias Presentes ${ }^{16}$, que apesar de não ser especificamente um trabalho com História Oral, levanta todos os problemas fundamentais que o historiador deve enfrentar.

Colocando-se no lugar de seu pai, um imigrante judeu-polonês que vive na cidade do México e que é abordado por uma jovem estudante de sociologia munida de gravador, perguntas ansiosas e "método científico", Woldenberg narra o inusitado, explicitando a angústia e o desconcerto de um entrevistando que se vê impedido de contar a "sua verdade".

Woldenberg ensina que o valor da memória não está naquilo que o narrador possa esclarecer, informar - "para isso existem os livros", como ele mesmo diz - mas antes naquilo que ele pode transmitir como experiência vivida e revivida, como realidade subjetiva e única, como sabedoria, como "aura" - no sentido benjaminiano ${ }^{17}$.

Woldenberg nos mostra como esta matéria, fruto de uma experiência tão incrustrada na vivência como um todo, que é a entrevista, é também prenhe não só de sentimentos, sonhos e imagens subjetivas, mas também de conceitos, idéias e representações sociais. Nela está uma dimensão mais profunda da objetividade, que se alcança através da subjetividade.

A busca da experiência subjetiva, a qual se chega pela inversão dos papéis - isto é, o pesquisador passa a ser aquele que não sabe o que é importante para o outro e assim não conduz a entrevista -, não se contrapóe, portanto, à pesquisa ou à interpretação científica. Muito pelo contrário, esta forma de trabalho, ao mesmo tempo que produz documentos para o estudo da sociedade, sua cultura e sua história, preserva o que existe de mais essencial

16 WOLDENBERG, José, Las Ausencias Presentes, México, Cal y Arena, 1992.

17 BENJAMIN, Walter. "O Narrador. Considerações sobre a Obra de Nikolai Leskov" in Magia e Técnica, Arte e Política; Ensaios sobre literatura e história da cultura. Obras Escolhidas Vol. 1. Trad. Sergio Paulo Rouanet. 3. Ed. São Paulo, Brasiliense, 1987. 
e importante em uma história individual: sua dimensão prática, épica, da transmissão da experiência humana.

A conciliação destes dois propósitos vem sendo a preocupação de autores que encontraram nas experiências da Nova Antropologia norte-americana de Geertz, Harari, Clifford e Marcus ${ }^{18}$, uma base teórica e metodologica para a História Oral.

Autores como Daphne Patai nos Estados Unidos e José Carlos Sebe Bom Meihy no Brasil ${ }^{19}$, têm buscado rediscutir as bases da moderna História Oral a partir de uma perspectiva onde a questão da colaboração - da relação entre entrevistador e entrevistado - assuma novas feições.

Bom Meihy e Patai não vêem na História Oral uma forma de "resgatar" o passado e "reconstruir" a realidade social a partir do discurso "fidedignamente" transcrito do "informante". Na verdade, ao invés disto, entendem a História Oral como método que permite a invenção de um discurso que se estabelece na interação entre pesquisador e narrador, enquanto sujeitos culturais e históricos, e que recria o passado a partir do presente.

Neste sentido, as formas tradicionais de se entender a relação entre sujeito e objeto já não mais operam aqui. Também perdem significado conceitos recorrentes da sociologia tradicional como "amostragem", "neutralidade", "transcrição fidedigna".

Para Bom Meihy e Patai, está claro que o pesquisador não apenas interage na rememoração e na construção do discurso do narrador no momento da entrevista, mas que ele também atua como recriador da entrevista através da transposição do discurso oral para o escrito. Neste sentido, ele deve se assumir como verdadeiro co-autor do documento, na medida em que a transposição não se limita apenas em transcrever a palavra dita. Na verdade, ela é um trabalho de reinvenção, de interpretação, como na montagem de uma peça de teatro. Entrentanto, ao contrário da dramaturgia tradicional, neste "teatro da linguagem" - como coloca Roland Barthes ${ }^{20}$ - é a cena - no caso

18 HARARI, Josue V., Textual Strategies; Prespectives in Past-Structuralism Criticism. Ithaca/New York, Cornell University Press, 1979; CLIFFORD, James \& MARCUS, George E., Writing Culture; The Poetics and Politics of Ethnography. Los Angeles, University of California Press, 1986.

19 Ver de PATAI, Daphne, Brazilian Women Speak: Conteporary Life Stories, New Brunswick and London, Rutgers University Press, 1988. E de BOM MEIHY, José Carlos Sebe, A Colônia Brasilianista; História Oral de Vida Acadêmica. São Paulo, Nova Stella, 1990, e também Canto de Morte kaiová: História Oral de Vida. São Paulo, Loyola, 1991.

20 BARTHES, Roland, "Authors and Writers", in SONTAG, Susan A Barthes Reader, New York, Hill and Wang, 1982. 
GALLIAN, Dante Marcello Claramonte. O historiador como inquisidor ou como antropologo? Um questionamento para os "historiadores orais".

a entrevista, enquanto "espetáculo" verbal, ambiental, emocional, gestual que se recria no texto.

Aqui o autor tem licença para reinventar e interpretar, porém não para desvirtuar o discurso do outro, pois, apesar de se utilizar de estratégias literárias, História Oral não é instrumento da ficção. A História Oral, antes de tudo, deve assumir um compromisso ético com o narrador, apresentando a "transcriação" como um produto de co-autoria, pois o narrador precisa, necessariamente, nela se reconhecer.

Ao mesmo tempo, todo este trabalho visa, fundamentalmente, a produção de um texto que deve se instituir como documento, passível de ser interpretado. Por isso mesmo, a explicitação e reconhecimento da inter-subjetividade em todas as etapas do processo de criação do texto tornam-se muito importantes: elas permitem com que as conclusões e afirmações sobre o narrador, sua história e sua cultura sejam mais consistentes e objetivas.

Portanto, assim como o antropólogo e o etnógrafo de que fala Clifford Geertz, o historiador que produz sua documentação através do trabalho de campo com entrevistas, ao estar consciente da disposição dialógica e não neutra que fundamenta o texto que ele produziu, tem a tarefa de assumir seu papel nesta produção. Um papel que não se limita ao de simples entrevistador, mas que, inclusive como entrevistador, se apresenta como o de autor. Tal como o antropólogo de Geertz ele deve apresentar-se na primeira pessoa, não apenas como pesquisador representante da ciência, mas como sujeito, indivíduo, pessoa - alguém que além de método, hipóteses e intenções científicas, traz também para o campo e para o texto suas impressões, sentimentos, pré-conceitos e toda uma gama infinita de disposiçóes pessoais e culturais.

Antes de tudo, antes mesmo de buscar convencer o leitor e a si mesmo de alguma verdade histórica ou cultural, o historiador deverá convencer de que ele "esteve lá"; que foi ele quem entrevistou, quem transcreveu e quem recriou. Pois apenas desta forma ele poderá "desenredar os diferentes fios que formam o tecido factual desses diálogos" que constituem os textos da História Oral e chegar a conclusões mais consistentes e objetivas sobre a história e a realidade cultural que ele pretende compreender.

\section{BIBLIOGRAFIA}

BARTHES, Roland, "Authors and Writers", in SONTAG, Susan A Barthes Reader, New York, Hill and Wang, 1982.

BENJAMIN, Walter, "O Narrador. Consideraçóes sobre a Obra de Nikolai Leskov" in Magia e Técnica, Arte e Política; Ensaios sobre literatura e história da cultura. Obras Escolhidas Vol. 1. Trad. Sergio Paulo Rouanet. 3. Ed. São Paulo, Brasiliense, 1987. 
R. Hlstória, Såo Paulo, n. 125-126, p. 93-103, ago-dez/91 a jan-jul/92.

BOM MEIHY, José Carlos Sebe, A Colônia Brasilianista; História Oral de Vida Acadêmica. Sảo Paulo, Nova Stella, 1990.

Canto de Morte kaiová: História Oral de Vida. Săo Paulo, Loyola, 1991.

BURNER, Edward M. and PLATTNER, Stuart, Text, Play, and Story: The Construction and Reconstruction of Self and Society. Washington, American Ethnological Society, 1984.

CLIFFORD, James \& MARCUS, George E., Writing Culture; The Poetics and Politics of Ethnography. Los Angeles, University of California Press, 1986.

FRASER, Ronald, Blood of Spain; an Oral History of Spanish Civil War. New York, Pantheon books, 1979.

GEERTZ, Cliford, El Antropologo como Autor, Barcelona, Paidos Studio, 1989.

GINZBURG, Carlo, "O Inquisidor como Antropólogo" in América, Américas, Revista Brasileira de Historia, São Paulo. ANPUH/Marco Zeto, n. 21 - setembro 90/ fevereiro 91, pp. 9-20.

HARARI, Josué V., Textual Strategies; Prespectives in Post-Structuralism Criticism. Ithaca/New York, Cornell University Press, 1979.

HENIGE, David P., Oral Historiography. London/New York, Longman, 1982.

LUMMIS, Trevor, Listening to History, New Jersey, Barnes \& Nobel Books, 1987.

PATAI, Daphne, Brazilian Women Speak: Conteporary Life Stories, New Brunswick and London, Rutgers University Press, 1988.

THOMPSON, Paul, The Voice of Past: Oral History. Oxford, Oxford Press, 1978.

VESENTINI, Carlos Alberto, A Teia do Fato; uma proposta de estudo sobre memória histórica. Tese de doutoramento, mimeo., São Paulo, FFLCH - USP, 1982.

WOLDENBERG, José, Las Ausencias Presentes, México, Cal y Arena, 1992.

ABSTRACT: To call the attention of the historians who work with documents of dialogue structure, especially those derived of the technique of Oral History, to the episthemological and methodological problems of the New Anthropology is the main objective of this article.

Starting from the analogy which historian Carlo Ginzburg proposes between the anthropologist and the inquirer, the purpose is to put back into discussion the problem of the relationship between the researcher and the narrator in the process of creating and interpreting oral sources.

KEY-WORDS: Oml History, Anthropology, Interviewer-interviewed relationship, Dialogue documents, Oral sources. 